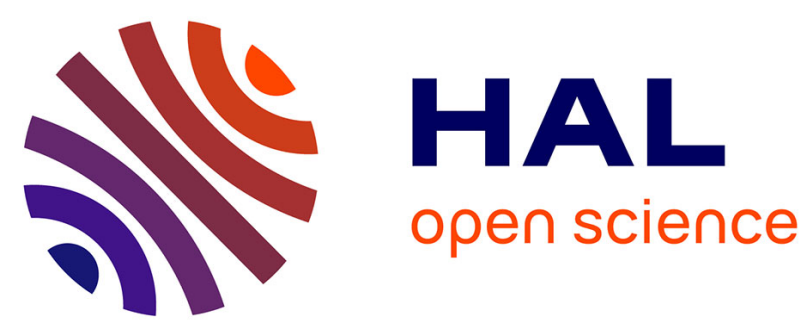

\title{
A multiphase Eulerian approach for modelling the polymer injection into a textured mould
}

Rebecca Nakhoul, Patrice Laure, Luisa Silva, Michel Vincent

\section{To cite this version:}

Rebecca Nakhoul, Patrice Laure, Luisa Silva, Michel Vincent. A multiphase Eulerian approach for modelling the polymer injection into a textured mould. International Journal of Material Forming, 2018, 11 (1), pp.53-66. 10.1007/s12289-016-1328-1 . hal-01796898

\section{HAL Id: hal-01796898 \\ https://hal.science/hal-01796898}

Submitted on 24 Oct 2019

HAL is a multi-disciplinary open access archive for the deposit and dissemination of scientific research documents, whether they are published or not. The documents may come from teaching and research institutions in France or abroad, or from public or private research centers.
L'archive ouverte pluridisciplinaire HAL, est destinée au dépôt et à la diffusion de documents scientifiques de niveau recherche, publiés ou non, émanant des établissements d'enseignement et de recherche français ou étrangers, des laboratoires publics ou privés. 


\title{
A multiphase Eulerian approach for modelling the polymer injection into a textured mould
}

\author{
Rebecca Nakhoul ${ }^{\dagger}$, Patrice Laure ${ }^{\star,}$, Luisa Silva $^{\ddagger}$, and Michel Vincent ${ }^{\dagger}$ \\ ${ }^{\dagger}$ MINES ParisTech, PSL - Research University, CEMEF - Centre for material forming, CNRS UMR \\ 7635, Sophia-Antipolis, France \\ ^Laboratoire J.A. Dieudonné, Université de Nice Sophia-Antipolis, CNRS UMR 7351, Nice, France \\ ${ }^{d d a g}$ ICI, Ecole Centrale de Nantes, Nantes, France
}

19 November 2016

\begin{abstract}
Micro-injection moulding is frequently used for the fabrication of devices in many different fields such as micro-medical technologies, micro-optics and micro-mechanics thanks to its effectiveness for mass production. This work focuses mainly on offering numerical methodology to model the injection into textured moulds. Such approach can predict the different filling scenarios of the micro-details and consequently can provide optimal operating conditions (mould and melt temperatures, flow rate) according to the desired final part quality. In fact, numerical simulations made with industrial software can only describe the injection process at the macroscopic scale where the micro details are not detected. Although the melt temperature and front evolution are tracked throughout time, neither the micro details nor the local heat transfer are properly represented. Since the latter impacts the local viscosity and solidification, simulation of both mould and cavity temperature evolutions is primordial to insure a complete and accurate representation of textured mould filling. The present computations are made at both macro- and micro- scales by using a full Eulerian approach in which the three phases (melt, mould and air) are described by level-set functions. Our numerical approach is checked to the replication of a textured mould for which two dimensional computations are relevant. This replication is properly modelled by taking into account viscosity dependence with temperature in the thermal boundary layer at the melt/mould interface. In particular the expected solidification below a specific temperature is taken into account by either increasing drastically the viscosity or by imposing a vanishing velocity by penalty method. The influence of flow rate and mould temperature are also analysed whereas it is shown that the surface tension can be neglected during injection stage.

Keywords: Micro-injection moulding ; FEM modelling ; Eulerian Formulation ; heat transfer ; polymer
\end{abstract}

\section{Introduction}

A micro moulded piece can be either a part with a weight, less than $1 \mathrm{mg}$, or a classical size part with micro details with a wall thickness smaller than $100 \mu m$ [15, 2, 13, 3, 39]. This paper focuses on the second type of product and the challenge is to replicate on the plastic object micro-details of the cavity surface [40, 43, 25].

In the last decades, micro-injection moulding was rated as the most used micro-moulding technique. It presents a wide range of devices, like micro-mechanics, micro-optics, micro-medical and micro-chemical applications [18, 19, 32, 33, 34], with good cost-effectiveness ratio for mass production.

Numerical simulation has proven to be a pertinent tool for modelling conventional injection moulding due to the numerous parameters involved in this process. Modelling micro-injection moulding faces even other challenges since the same physical concepts cannot be applied at both macro and micro scales. Firstly, it can be difficult to scale down the macroscopic physical properties, as mentioned in [29]. In addition, several factors or phenomena, commonly neglected in macroscopic moulding simulations, have significant impact on microinjection accuracy [14] due to the greater surface-volume ratio. Some of these neglected components are the surface tension, the surface roughness, the heating of the melt by viscous dissipation, the fast cooling due to the thin wall thickness and the use of an evacuation system for the air [42]. Note that the melt behaviour should as well be inspected closely in micro-injection, where more significant shear rates are involved [29]. 
For all the reasons mentioned above, a numerical tool for modelling micro-injection is highly desirable. In the studied case, the aim is to get the flow front evolution in order to predict the filling ratio of the textured mould (especially the last filled sections). For these simulations, the front tracking and the heat transfer by conduction and convection (at the contact with the mould) have to be very accurately modelled.

Several works attempted to model micro-injection moulding using commercial software dedicated to conventional injection moulding and led to the conclusion that these software have to be improved in order to properly simulate the micro-injection processes [37]. The simplest is to add the ingredients related to high flow rate (wall slip, mould/melt heat transfer coefficients, roughness) in order to get a good agreement with experimental measurements of the pressure drop as in [27, 38, 28, 12]. Concerning cavity filling, specific improvements have to be done. A hybrid numerical technique mixing Hele-Shaw and general momentum equation has been developed in [41] to provide precise flow simulation around the micro-structures. Computations performed by the authors showed that mould/melt heat transfer coefficients and injection speed are very important factors to determine the filling depth in micro-structures. However, to get a good agreement with experimental observations, they have established that a decrease of the heat transfer coefficient and the occurrence of wall-slip have to be taken into account in micro-channels. Very recently [21, 22], 3D micro- and nanostructures filling were computed with Moldflow $\AA$ [17] and Comsol $\AA$ [8]. These authors performed these computations at different scales, the boundary conditions at lower scale being deduced from computation made at upper level. However, the temperature inside the mould was not computed and the accurate thermal behaviour at lower scale was obtained by increasing thermal coefficients.

In this paper, we first use a commercial software, $\operatorname{Rem} 3 \mathrm{D} \cap$ [10, 23], capable of modelling three-dimensional injection moulding configurations. Section 2 introduces firstly the assumptions considered in our macro-micro modelling: the ability of the Carreau-Yasuda law coupled to the Williams-Landel-Ferry (WLF) model to describe the rheological behaviour; how a mid-plane simulation is sufficient to study the part filling; the importance of the increase of melt temperature from viscous dissipation. Then, a multiphase Eulerian approach is adopted and detailed. The different phases are described implicitly using a level-set method [6] and one single mesh is used over the whole domain. Instead of determining a polymer/mould heat transfer coefficients [42, 22], we propose to calculate the temperature evolution in both the melt and the mould [9]. Therefore, heat transfers on the interface are implicitly taken into account by the formulation, independently of the shapes of the textured zone. Global properties are determined from each phase by using mixture laws [7] and the solved equations are presented in section 2.4. In addition, the mesh is anisotropically refined by moving nodes to get an accurate representation of the interface and reduce errors on the computed flow [5]. In fact, the immersion of a phase function representing the mould modifies how the accuracy changes with the mesh size $h$. For example, the precision for the velocity evolves in $\mathcal{O}(h)$ for the immersed method instead of $\mathcal{O}\left(h^{2}\right)$ for linear trial functions [20]. This lack of accuracy is compensated by the use of an anisotropic mesh which allows reaching a required precision with a reduced number of nodes. Finally, the adopted strategy to pass from the macroscopic to the microscopic scale is described in section 3

Computations were performed with polypropylene (PP) which is one of the most common thermoplastic polymers used in a variety of products and is easily and widely transformed by the injection moulding. Moreover, it has been recently used to obtain replication of submicrometer features by injection (microinjection) molding [36, 31]. For example polypropylene is used for biomedical devices which have a short time contact with drugs (disposable syringes and catheters) where the aim is to have a plastic hydrophobic surface to improve the displacement of the plunger inside the syringe.

We restrict our study to the filling stage in order to determine whether or not the micro-details are completely filled, to obtain the position of the final flow front and the temperature distribution. Though this point is not treated in this paper, we should mention that numerical tools can be used also to predict post-processing quality, based on physical notions of residual stresses, warpage and shrinkage which can appear during the cooling and packing stages.

\section{Multiphase Eulerian approach}

A multiphase Eulerian approach is based on the definition of one global computational domain $\Omega$ in which all the interacting phases are immersed. One mesh is used all over the domain where three different phases are present: the melt, the mould and the air. They are denoted, respectively $f, m$ and $a$. To determine the boundary 
of each phase, distance functions are used. Then the evolution of phases is obtained either by computing again the distance for an imposed motion or by solving an advection equation like in the case of determining the polymer/air interface. Mixture laws are used to transform local properties into global ones, defined all over the computational domain.

\subsection{Level Set method}

The level set method consists first in introducing a signed distance function $\alpha$ between a point $x$ and the boundary $\Gamma$ of a body or phase $P$ :

$$
\alpha(x, t)=\left\{\begin{array}{cl}
-d(x, \Gamma) & \text { if } x \in \Omega / P \\
0 & \text { if } x \in \Gamma \\
d(x, \Gamma) & \text { if } x \in P
\end{array}\right.
$$

where $d(x, \Gamma)$ is the distance of point $x$ to the interface $\Gamma$. Then, the distance function is convected by $v$, the velocity solution of the monolithic system arising from flow constitutive equation:

$$
\left\{\begin{array}{l}
\frac{\partial \alpha}{\partial t}+v \cdot \nabla \alpha=0 \\
\alpha(t=0, x)=\alpha_{0}(x)
\end{array}\right.
$$

A re-initialization step was proven to be necessary to maintain distance function geometrical properties, namely $|\nabla \alpha|=1$. Moreover, it is also possible to restrict this level set function to a narrow interval $[-\varepsilon, \varepsilon]$ around the interface, by applying a hyperbolic tangent filter [7]

$$
\phi=\varepsilon \tanh \frac{\alpha}{\varepsilon}
$$

The displacement of this new local distance function $\phi$ is obtained by solving the following equation [30, 7] :

$$
\left\{\begin{aligned}
\frac{\partial \phi}{\partial t}+(v+\lambda u) \cdot \nabla \phi & =\lambda s(\phi) g(\phi) \\
\phi(t=0, x) & =\phi_{0}(x)
\end{aligned}\right.
$$

where $s$ is the sign function ( -1 outside the phase and +1 inside), $u$ the reinitialization velocity and $g(\phi)=$ $1-\left(\frac{\phi}{\varepsilon}\right)^{2}$. The last factor, $\lambda$, is equal to $h / \Delta t$ where $h$ and $\Delta t$ denote respectively, the mesh size and the time step.

Since three phases are involved (mould, air, fluid), two distance functions should be used. For mould and fluid, a local distance function $\phi_{i}$ is associated and the air phase is deducted by the complementary. This technique enables us to associate different physical properties to each phase and every phase has different local properties $\beta_{i}$ ( $\beta_{i}$ may be viscosity, the density, the thermal conductivity and the heat capacity). A global property $\beta$ is defined using smooth Heaviside function $H_{i}^{\varepsilon}$ :

$$
\beta=\sum_{i=1}^{n-1} H_{i}^{\varepsilon}\left(\phi_{i}\right) \beta_{i}+\left(1-\sum_{i=1}^{n-1} H_{i}^{\varepsilon}\left(\phi_{i}\right)\right) \beta_{n}
$$

In this expression, $n$ is the number of phases present in the domain. The last phase (labelled $n$ ) represents the air and so one only needs to determine the $n-1$ phase functions.

Note that the smooth Heaviside function depends on the parameter $\varepsilon$ used to truncate the level set function. It insures a smooth transition between the different phases and in this work,

$$
H_{i}^{\varepsilon}=\frac{1}{2}\left(1+\frac{\phi_{i}}{\varepsilon}\right)
$$

is used. Since the interface between the phases is known implicitly, the filtered level set function $\phi$ is interpolated and an optimal mesh is obtained using an anisotropic mesh adaptation based on an a posteriori interpolation error [5, 7] (detailed in section 2.2.). 


\subsection{Anisotropic Mesh Adaptation}

Anisotropic mesh adaptation enables to capture discontinuities or gradients of the solution in flow, thermal, kinetical situations [5, 7], with a good accuracy at a very low extra number of elements. Building unstructured anisotropic meshes may be based on local mesh modifications, using a metrics field to redefine the lengths [4] and a recently developed procedure optimal in terms of determining this metrics field.

Let us consider mesh topologies composed of simplex elements (triangles, tetrahedra ...), $K$ being a $d$ simplex ( $d$ is the spatial dimension) composed of $D=d+1$ vertices. The described mesh generator adapts an initial mesh by iteratively modifying and optimizing it locally [4,11]. This technique consists in the improvement of the quality of local cavities composed of clusters of elements by remeshing. Two principles are enforced: the minimal volume, which gets the conformity of the mesh, with no element overlaps; the geometrical quality distribution ensuring that, if the minimal volume provides several possible cavity re-triangulations, then the one chosen is such that it provides the best worst element. The geometrical quality, $Q(K)$, is evaluated for each element $K$ and varies from 0 (worst) to 1 (best quality). It depends on $\underline{M}_{K}$, the metric of the element $K$, which is thus the information needed by the mesher to generate a new mesh.

Construction of $\underline{M}$ may be done using the interpolation error analysis on a solution field, for example $u$, which may be velocity, phase functions, temperature or even a vector containing all the important variables. Following [5], let us define the edge vector as $\vec{X}^{i j}=\vec{X}^{j}-\vec{X}^{i}$, connecting nodes $i$ and $j$, and the edge length distribution tensor at $i$ as

$$
\underline{X}^{i}=\frac{1}{|\Gamma(i)|} \sum_{j \in \Gamma(i)} \vec{X}^{i j} \otimes \vec{X}^{i j}
$$

where $\Gamma(i)$ represents the nodes that share an edge with $i$. It may be established that the metrics computed at the node is: $\underline{M}^{i}=\frac{1}{d}\left(\underline{X}^{i}\right)^{-1}$.

Let us suppose that one wishes to generate a new mesh that equidistributes in each edge a constant target interpolation error, $e_{\text {target }}$. It has been previously shown [6] that this target error can be directly linked to a fixed number of nodes $N$ (which may also be related with the available CPU power), $e_{\text {target }}=e_{\text {target }}(N)$. An a posteriori interpolation error analysis states that the error along an edge $i j$ on the solution field $u, e^{i j}$, is $e^{i j}=\nabla u^{i j} \cdot \vec{X}^{i j}$, where $\nabla u^{i j}=\nabla u^{j}-\nabla u^{i}$, nodal gradients in $i$ and $j$ obtained with a gradient recovery procedure [5].

The optimal stretch factor, $s^{i j}$ that must be applied to edge $\mathbf{X}^{i j}$ to attain $e_{\text {target }}$ may now be used to compute the target metric given to the mesher, which allows the new mesh generation:

$$
s^{i j}=\frac{e_{\text {target }}(N)}{e^{i j}} \text { and } \widetilde{\underline{M}^{i}}=\frac{1}{d}\left[\frac{1}{|\Gamma(i)|} \sum_{j \in \Gamma(i)}\left(s^{i j}\right)^{2} \vec{X}^{i j} \otimes \vec{X}^{i j}\right]^{-1}
$$

An illustration of the type of result obtained in adaptation around the texturation and fluid-air interface is illustrated in Figure1

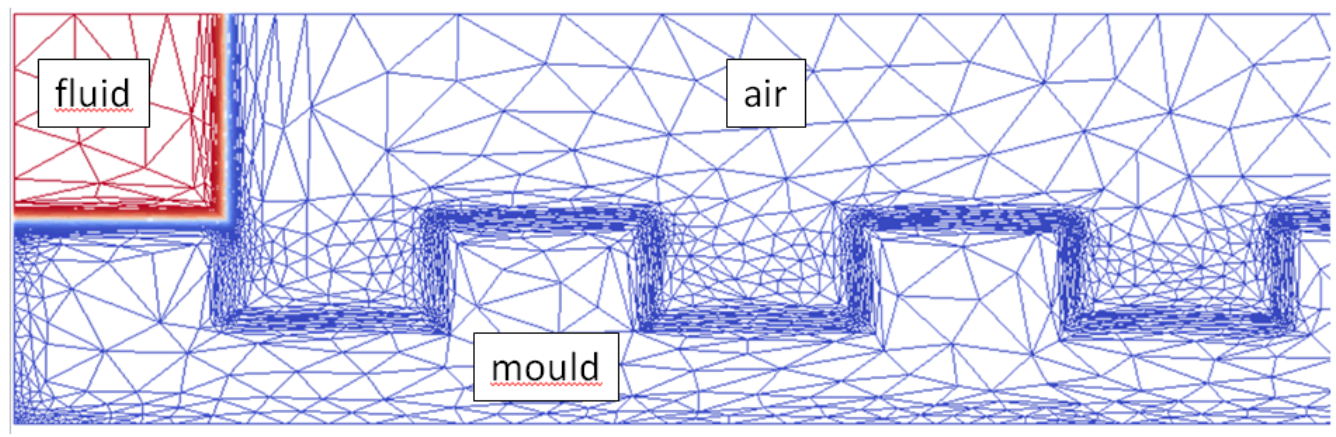

Figure 1: Adapted mesh to accurately represent, in an implicit way, the interface between air, fluid and the mould shape. 


\subsection{Monolithic thermo-mechanical problem}

The proposed monolithic formulation (9) consists in finding the velocity $v$, pressure $p$ and the temperature $T$ all over the global domain $\Omega$. It gathers the momentum conservation equation (9), the mass conservation equation (9ii), the energy equation (9iii) and an appropriate set of boundary conditions, which are, assuming the incompressibility

$$
\left\{\begin{aligned}
\rho \frac{d v}{d t}=\nabla \cdot(2 \eta(\dot{\bar{\varepsilon}}) \dot{\epsilon}(v))-\nabla p & \text { (i) } \\
\nabla \cdot v=0 & \text { (ii) } \\
\rho C_{p} \frac{d T}{d t}=\nabla \cdot(k \nabla T)+2 \eta(\dot{\bar{\varepsilon}}) \dot{\epsilon}(v): \dot{\epsilon}(v) & \text { (iii) } \\
\text { +initial and boundary conditions } & \text { (iv) }
\end{aligned}\right.
$$

where $\eta$ is the viscosity, $\dot{\varepsilon}$ is the rate of strain tensor, $\dot{\bar{\varepsilon}}$ the generalized shear rate defined as $\dot{\bar{\varepsilon}}=\sqrt{2 \dot{\varepsilon}(v): \dot{\varepsilon}(v)}$, $\rho$ the density, $C_{p}$ the specific heat capacity and $k$ is the thermal conductivity which is assumed to be constant in each domain (polymer, mould, air). The last right hand side term in Eq. (9iii) is the heat released by viscous dissipation. The parameters $\eta, \rho, C_{p}$ and $k$ are defined all over the domain via mixing laws (see Eq. (5)). Examples of values used for the mould and the air are given in Table 1 .

\begin{tabular}{|l|c|c|}
\hline & mould & air \\
\hline Thermal conductivity $k\left(W . m^{-1} \cdot K^{-1}\right)$ & 80.2 & 0.0262 \\
\hline Heat capacity $C_{p}\left(J . \mathrm{kg}^{-1} . K^{-1}\right)$ & 444 & 1004 \\
\hline density $\rho\left(K g / \mathrm{m}^{3}\right)$ & 7860 & 1.14 \\
\hline viscosity $\eta(P a . s)$ & $10^{3} \times \max \left(\eta_{\text {melt }}\right)$ & $10^{-3} \times \min \left(\eta_{\text {melt }}\right)$ \\
\hline
\end{tabular}

Table 1: Mould and air properties used in the computations.

Note that the viscosities for mould and air are chosen with respect to the melt viscosity by taking into account the following constraints: for the numerical procedure, the matrix conditioning is better if the ratio between maximal and minimal viscosities through the computational domain is less than $10^{10}$; the mould viscosity has to be important enough in order to have an almost null velocity inside the mould; the air viscosity should be small enough to guarantee the fountain flow at the air-melt interface.

The polymer melt is a viscous non-Newtonian fluid and thus the viscosity depends highly on the shear rate. The shear thinning behaviour of the melt is approached by a Carreau-Yasuda law at the reference temperature $T_{\text {ref }}$ :

$$
\eta\left(T_{\mathrm{ref}}, \dot{\varepsilon}(v)\right)=\eta_{0}\left(T_{\mathrm{ref}}\right)\left[1+\left(\frac{\eta_{0}\left(T_{\mathrm{ref}}\right)}{\tau} \dot{\bar{\varepsilon}}(v)\right)^{a}\right]^{\frac{m-1}{a}}
$$

where $m$ is the power law index, $\eta_{0}$ is the viscosity at zero shear rate, $\tau$ is the shear thinning stress and $a$ is a non-dimensional parameter describing the transition between the Newtonian zone and the power law one.

The principle of time-temperature superposition gives the evolution of the viscosity with the temperature

$$
\eta_{0}(T)=\eta_{0}\left(T_{r e f}\right) \cdot a_{T}
$$

There are several choices to express the temperature dependence of factor $a_{T}$. The most used are the Arrhenius and Williams-Landel-Ferry (WLF) [35] models. The Rem3D $\AA$ data base proposes a variant of the WLF model where the shift factor $a_{T}$ is expressed in terms of the melt temperature $T$, a reference temperature $T_{r e f}$ and a temperature $T_{l}$ :

$$
\log a_{T}=-\left[\frac{C_{1}\left(T-T_{l}\right)}{C_{2}+\left(T-T_{l}\right)}\right]+\left[\frac{C_{1}\left(T_{r e f}-T_{l}\right)}{C_{2}+\left(T_{r e f}-T_{l}\right)}\right]
$$


in which $C_{1}$ and $C_{2}$ are positive constants obtained by averaging values for several polymers. The temperature $T_{\text {ref }}$ is the temperature chosen within the range of rheological measurements (it corresponds also to its optimal temperature for injection process) and $T_{l}$ is a temperature used to fit these measurements. The values used in our computations are given in Table 2. Note that this limit temperature $T_{l}$ is lower than the estimated solidification temperature for polypropylene which is around $T_{s}=117^{\circ} \mathrm{C}$ (the crystallisation is here not taken into account).

\begin{tabular}{|l|c|c|}
\hline Solidification temperature $T_{s}$ & 117 & ${ }^{\circ} \mathrm{C}$ \\
\hline Limit temperature $T_{l}$ & 62.5 & ${ }^{\circ} \mathrm{C}$ \\
\hline Reference temperature $T_{r e f}$ & 205 & ${ }^{o} \mathrm{C}$ \\
\hline Thermal conductivity $k_{f}$ & 0.16 & $\mathrm{~W} / \mathrm{m}^{\circ} \mathrm{C}$ \\
\hline Heat capacity $C_{p_{f}}$ & 2789 & $\mathrm{~J} / \mathrm{kg} \mathrm{g}^{\circ} \mathrm{C}$ \\
\hline Melt density $\rho_{f}$ & 729 & $\mathrm{Kg} / \mathrm{m}^{3}$ \\
\hline viscosity $\eta_{0}$ & 491 & $\mathrm{Pa.s}$ \\
\hline shear thinning Stress $\tau$ & 51673 & $\mathrm{~Pa}$ \\
\hline power index $m$ & 0.3 & \\
\hline Carreau parameter $a$ & 2 & \\
\hline$C_{1}$ & 8.86 & \\
\hline$C_{2}$ & 101 & ${ }^{\circ} \mathrm{C}$ \\
\hline
\end{tabular}

Table 2: Melt properties of polypropylene used (PP-PRO-FAX PD702 in Rem3D® database).

The rheology and thermo-physical data shown in Table 2 are usually sufficient to describe the velocity, pressure and flow front evolution with a commercial software such as Rem3Dß. But the description of the rheological behaviour and solidification in the boundary layer close to the mould is not an easy task.

From a numerical point of view, it is necessary to introduce a no-flow criterion. This is particularly crucial when modelling micro-cavity filling where the cooling time is short and has a great impact on the filling rate. In the case of a polypropylene, the cessation of flow is related to the crystallization. In this work, we chose a most simpler criterion related to a solidification temperature $T_{s}$. We can choose either to increase drastically the viscosity when temperature falls below $T_{s}[26]$ or to impose a null velocity as a Dirichlet condition which depends on the temperature. The first method can be achieved using an exponential function to artificially increase the viscosity below the "solidification" temperature $T_{s}$ :

$$
\begin{cases}\eta=\eta(T) & \text { if } T \geq T_{s} \\ \eta=\eta(T) e^{b\left(T_{s}-T\right)} & \text { if } T<T_{s}\end{cases}
$$

in which $b \in[0,1]$ is a parameter used to control the rate of solidification. To clarify how this modification acts on the viscosity, a comparison between the two relations (Eqs. (11) and (12) vs. Eqs (11) and (12) modified with Eq. (13) ) is illustrated in Figure 2. The new parameters, $T_{s}$ and $b$, depend on both the melt properties and process conditions. They should be carefully chosen by comparison with the existing experimental data.

The second method is built by adding a penalization term in the weak formulation which will depend on the solidification temperature (explained in the sequel of this paper). Note that similar no-flow temperature is also used in [21].

\subsection{Scaled equations}

As we plan to perform computations at different scales, it is convenient to deal always with a computational domain unit sized. Proceeding this way, computational parameters such as the time step, the size of mixing layer $\epsilon$, interpolation errors and even the number of nodes are the same for both the macro- and micro-scales. Therefore, we choose to scale the momentum and energy equations by taking a reference length $L_{r e f}$, a reference velocity $V_{\text {ref }}$, the melt thermal conductivity $k_{f}$ and the zero-shear viscosity $\eta_{0}$ as the scaling factors. We define the following non-dimensional variables:

$$
v^{*}=\frac{v}{V_{\text {ref }}}, x^{*}=\frac{x}{L_{r e f}}, t^{*}=\frac{t V_{\text {ref }}}{L_{r e f}}, \eta^{*}=\frac{\eta}{\eta_{0}}, p^{*}=\frac{p L_{r e f}}{\eta_{0} V_{r e f}}, k^{*}=\frac{k}{k_{f}}
$$




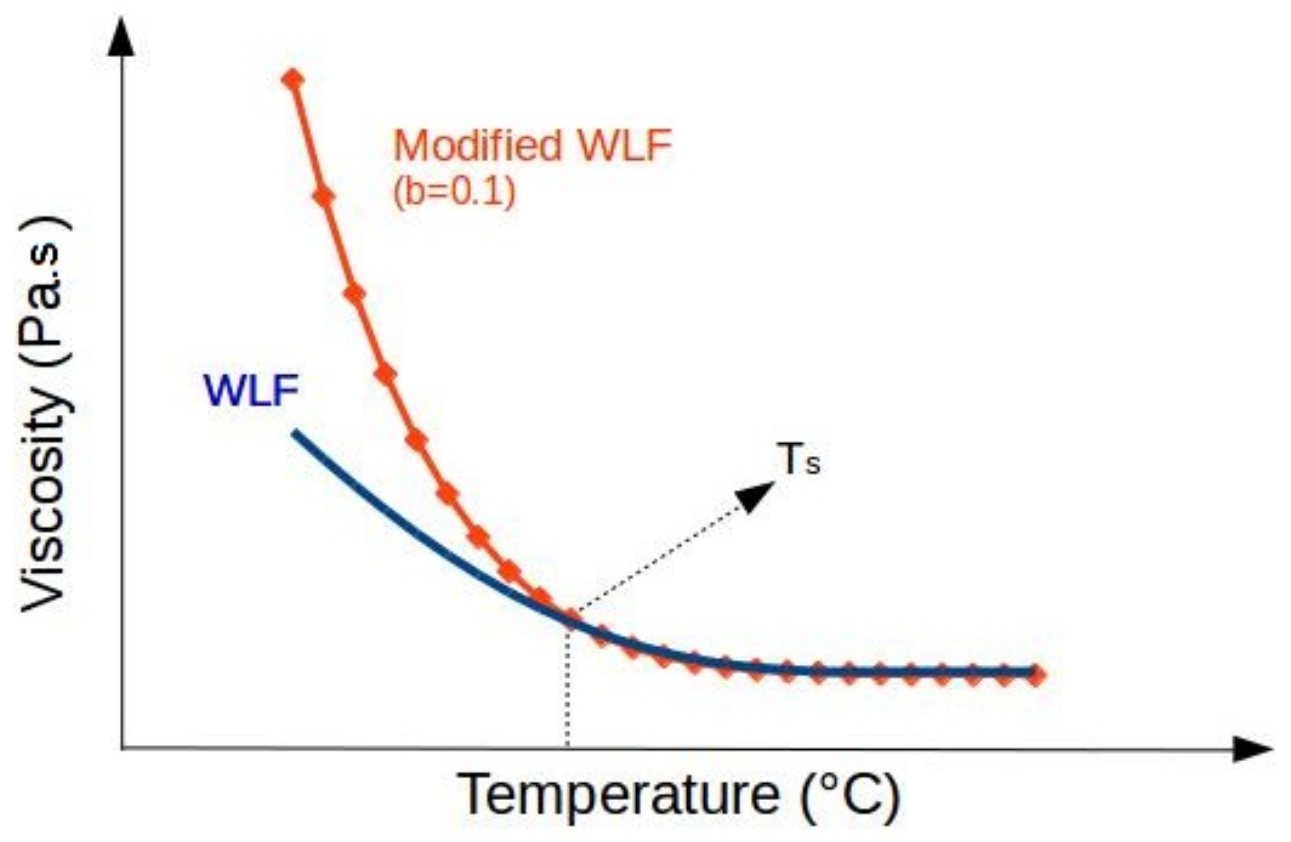

Figure 2: Illustration of the viscosity obtained using both WLF and the modified WLF relations with $b=0.1$ and $T_{s}=117^{\circ} \mathrm{C}$.

where $L_{r e f}$ is the horizontal range under consideration and $V_{r e f}$ is equal to either the mean velocity or the upper shear flow at meso- and micro- level respectively. Finally, equations (9) become (omitting the superscript $*$ ):

$$
\begin{aligned}
\frac{\rho V_{\mathrm{ref}} L_{\mathrm{ref}}}{\eta_{0}}\left(\partial_{t} v+v \cdot \nabla v\right) & =\nabla \cdot(2 \eta \dot{\varepsilon}(v))-\nabla p \\
\nabla \cdot v+\chi p & =0 \\
\frac{\rho C_{p} L_{\mathrm{ref}} V_{\mathrm{ref}}}{k_{f}}\left(\frac{\partial T}{\partial t}+v \nabla T\right)-\nabla \cdot(k \nabla T) & =\frac{\eta_{0} V_{\mathrm{ref}}^{2}}{k_{f}}(2 \eta \dot{\varepsilon}(v): \dot{\varepsilon}(v))
\end{aligned}
$$

The parameter $\chi$ in the mass conservation equation $(16)$ can be non null in the air domain. It is a numerical artefact added to deal with air entrapment. A high value of $\chi$ makes the air compressible and it will not prevent micro-features filling.

For the filling of small micro-features, the melt surface tension can be taken into account as the filling velocity is small as well as the characteristic dimension. The jump of the normal stress due to the surface tension reads in the scaled form,

$$
[[\sigma \cdot \mathbf{n}]]_{\Sigma}=\frac{\gamma}{\eta_{0} V_{\text {ref }}} \kappa \mathbf{n}
$$

where $\mathbf{n}$ is the normal to the fluid/air interface $\Sigma$ and $\kappa$ is its curvature, given by

$$
\kappa=\nabla \cdot \mathbf{n} .
$$

The scalar $\gamma$ is the surface tension between the two phases $\left(\sim 3010^{-3} \mathrm{~N} / \mathrm{m}\right.$ for the polypropylene/air interface). The dimensionless capillary number, $C a$, which gives the importance of surface tension forces with respect to viscous forces, is defined as follows:

$$
C a=\frac{\eta_{0} V_{r e f}}{\gamma}
$$

This number will be estimated during the computations in order to analyse if the surface tension may have an influence on cavity filling.

The numerical method used to solve the above equations is based on the use of a stable mixed formulation, which consists of continuous piecewise linear functions enriched with a bubble function for the velocity and 
piecewise linear functions for the pressure. A brief description of our mixed finite element method is presented in [6]. We only focus on the way to impose the no-flow condition by incorporating a penalty method in the formulation. The weak formulation of Navier-Stokes equations is written on suitable trial functional spaces $\mathcal{Q}$ and $\mathcal{V}$ and reads:

Find $(\mathbf{u}, p) \in \mathcal{V} \times \mathcal{Q}$ such that

$$
\begin{gathered}
\int_{\Omega} \rho d_{t} \mathbf{u} \cdot \mathbf{v}+\int_{\Omega} 2 \eta \epsilon(\mathbf{u}): \epsilon(\mathbf{v}) d \Omega-\int_{\Omega} p \nabla \cdot \mathbf{v} d \Omega= \\
\int_{\Omega} A_{P}(T) \mathbf{u} \cdot \mathbf{v} d \Omega+\int_{\Omega} \delta_{\Gamma}[[\sigma \cdot \mathbf{n}]] \cdot \mathbf{v} d \Omega \\
\int_{\Omega} \nabla \cdot \mathbf{u} q d \Omega=0
\end{gathered}
$$

where the penalty factor $A_{p}(T)$ is defined:

$$
A_{p}(T)= \begin{cases}0 & \text { if } T \geq T_{s} \\ 10^{6} \max \left(\eta_{\text {melt }}\right) & \text { if } T<T_{s}\end{cases}
$$

and $[[\sigma \cdot \mathbf{n}]]$ is the jump of the normal stress at the interface $\Gamma$ defined implicitly by $T=T_{s}\left(\delta_{\Gamma}\right.$ being the Dirac function associated to this interface). This latter term is added as the vanishing condition on the velocity and it is not compatible with the continuity of the normal stress involved in the classical Finite Element formulation.

\section{Methodology: from macroscopic to a microscopic scale}

As already noted in the introduction, the aim of this paper is to analyse the filling of micro-features during the

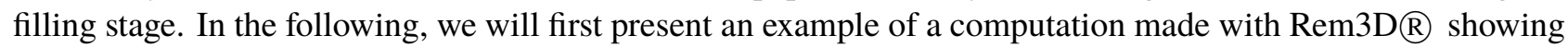
that in the textured zone the flow motion is purely two-dimensional. Then, we will present two dimensional multiphase computations which give a better description of the temperature profile in the layer close to the mould and allow us to determine the size of the boundary region where the temperature changes abruptly. It defines the zone of interest for micro-scale studies. Finally, computations will be made in this boundary layer in order to analyse texture filling.

\subsection{Computations at macro-scale with commercial software}

Rem3D $R$ is a commercial software capable of modelling the unsteady non-isothermal flow of a viscous nonNewtonian fluid in a mould cavity. Then, it computes the evolution of the melt front, temperature, velocity and pressure fields. The temperature is not computed inside the mould and a boundary condition for the energy equation must be specified at the cavity mould walls. We have the choice between a temperature, $T_{m}$, imposed on the cavity boundary or a condition on the flux depending of a regulation (or control) temperature $T_{c}$, given by

$$
-k_{f} \partial_{n} T=\frac{k_{m}}{e}\left(T-T_{c}\right)
$$

where $e$ is the distance between the location where the control temperature is applied and the wall in contact with the polymer and $k_{m}$ is the thermal conductivity of the mould steel. For sake of simplicity, we choose to impose the temperature at the wall (Dirichlet condition). The melt temperature is specified at the inlet, a sticking contact at the mould walls and a zero stress normal to the flow front.

The polypropylene described in Table 2 is injected in the cavity illustrated in Figures 3 This part has been experimentally used for characterizing micro-features replication [16, 31]: the rectangular plaque is $50 \mathrm{~mm}$ long and $15 \mathrm{~mm}$ wide; its thickness is $1 \mathrm{~mm}$. The piece exhibits micro features in the central square zone of $8 \mathrm{~mm}$. These micro details are uniform ribs in the transverse direction (perpendicular to the flow direction). Their depth and width are $10 \mu \mathrm{m}$ (see Fig. 5). They cannot be represented in Rem3D $\mathrm{R}$ because of mesh limitations.

The filling flow rate is $Q=25 \mathrm{~cm}^{3} / \mathrm{s}$ and the inlet temperature is $T_{f}=205^{\circ} \mathrm{C}$. The mould temperature $T_{m}$ is equal to $35^{\circ} \mathrm{C}$. The cavity is filled in approximately $0.1 \mathrm{~s}$ : the melt front arrives at the beginning of the textured zone at $t_{1}=0.074 \mathrm{~s}$, and, at the end of this zone around $0.006 \mathrm{~s}$ later. Finally, the melt flows through this textured area during $0.026 \mathrm{~s}$ until the melt fills the entire cavity. 


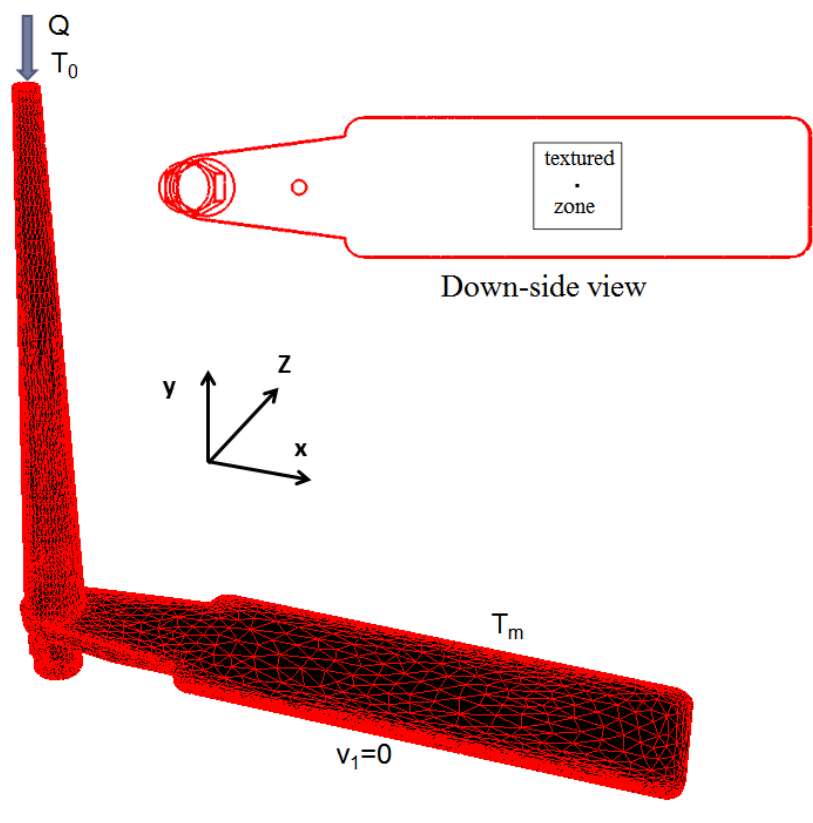

Figure 3: Cavity used in the macroscopic simulation: a $50 \mathrm{~mm}$ by $15 \mathrm{~mm}$ part and a thickness of $1 \mathrm{~mm}$ with a textured zone beginning at $21 \mathrm{~mm}$ from end wall. [16].

The evolution of the melt, the temperature and the velocity are tracked in time. Examples of obtained results are presented in Figure 4 for $t=0.0725 \mathrm{~s}$, before the fluid reaches the textured zone. The velocity and temperature fields are presented in Figures $4 \mathrm{~b}-\mathrm{c}$ on a transverse section.

One observes that the flow motion on the textured zone is mainly 2D (evolving in the $(x, y)$ plane) with a maximal velocity in mid-thickness around $2.5 \mathrm{~m} / \mathrm{s}$. The temperature reaches $210^{\circ} \mathrm{C}$, a temperature a little higher than the injection temperature because of the viscous dissipation. The maximum is probably not far from the walls where the shear rate is maximum, and decreases to the imposed mould temperature at the wall $\left(35^{\circ} \mathrm{C}\right)$ with a sharp gradient. However, the temperature close to the cavity walls is not well described due to approximation on the boundary conditions and lack of accuracy (the mesh has not enough nodes in this layer).

It is usual to introduce the following dimensionless numbers for the melt:

$$
P_{e}=\frac{L_{\mathrm{ref}} V_{\mathrm{ref}} \rho c_{p}}{k_{f}} ; R e=\frac{\rho V_{\mathrm{ref}} L_{\mathrm{ref}}}{\eta_{\mathrm{ref}}} ; B_{r}=\frac{\eta V_{\mathrm{ref}}^{2}}{k_{f}\left(T_{f}-T_{m}\right)} ; C_{a m}=\frac{k_{f} L}{\rho C_{p} V_{\mathrm{ref}} H^{2}}
$$

which are, respectively, the Péclet number, Reynolds number, the Brinkman number and the Cameron number. If the reference length is the length of rectangular cavity $(0.05 \mathrm{~m})$, the Péclet number is very high $\left(\sim 10^{6}\right)$ and means that the heat transfer by conduction will be limited in the mould boundary layer.

The Reynolds number is less than 0.01, therefore the flow motion for the melt remains stationary and the framework of this study is related to creeping flows. Finally, the Brinkman is around 100 meaning that the heat produced by viscous dissipation is not compensated by the conduction with cold walls. The Cameron number is less than $10^{-2}$ and that means also that the polymer temperature is changed in a very narrow boundary layer near the mould.

\subsection{Multiphase computation summary}

In micro-injection moulding, the thermal transfers play a key role and the heat exchanges at the scale of the microfeatures have to be studied closely. We propose to review the case from a different angle, at both macroscopic and microscopic scales, by performing two-dimensional multiphase computations. In this way, it is possible to accurately describe the textured cavities, microscopic details which could not be taken into account by Rem3D $\mathbb{R}$ software. The depth of the textured shape around $10 \mu \mathrm{m}$ is 100 times smaller than the part thickness. The form and direction of the micro cavities (see Figure 5) suggest that a 2D computation might be enough to give a clear idea of the melt behaviour in the textured zone. We have chosen a representative longitudinal section located in 

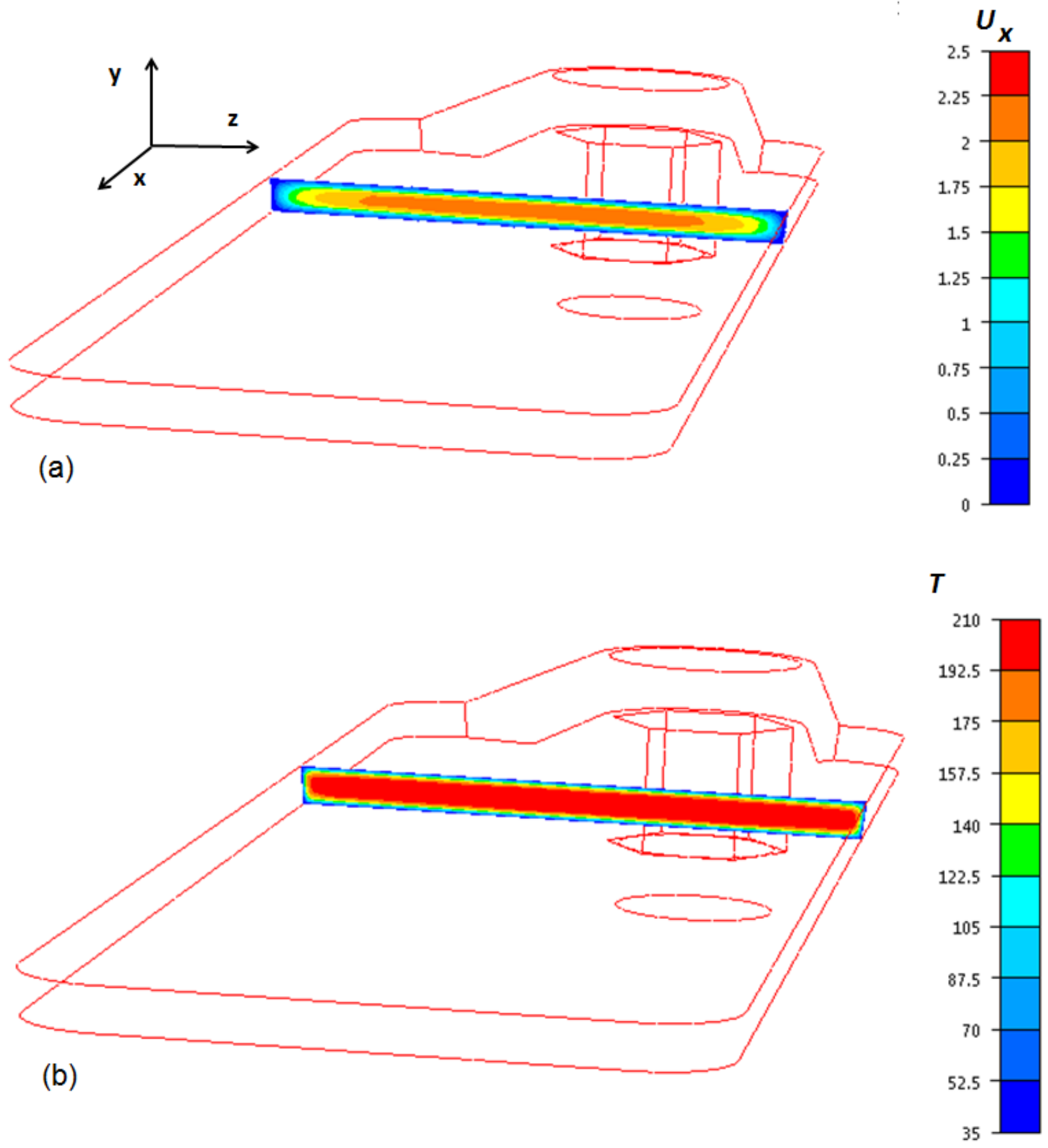

Figure 4: Velocity (a) and temperature (b) distributions in a transverse section of the cavity at $t=0.0725 \mathrm{~s}$. 
the centre of the cavity from which all needed data can be collected (mainly temperature and velocity values). The computational domain used in our calculations is depicted in Figure 5

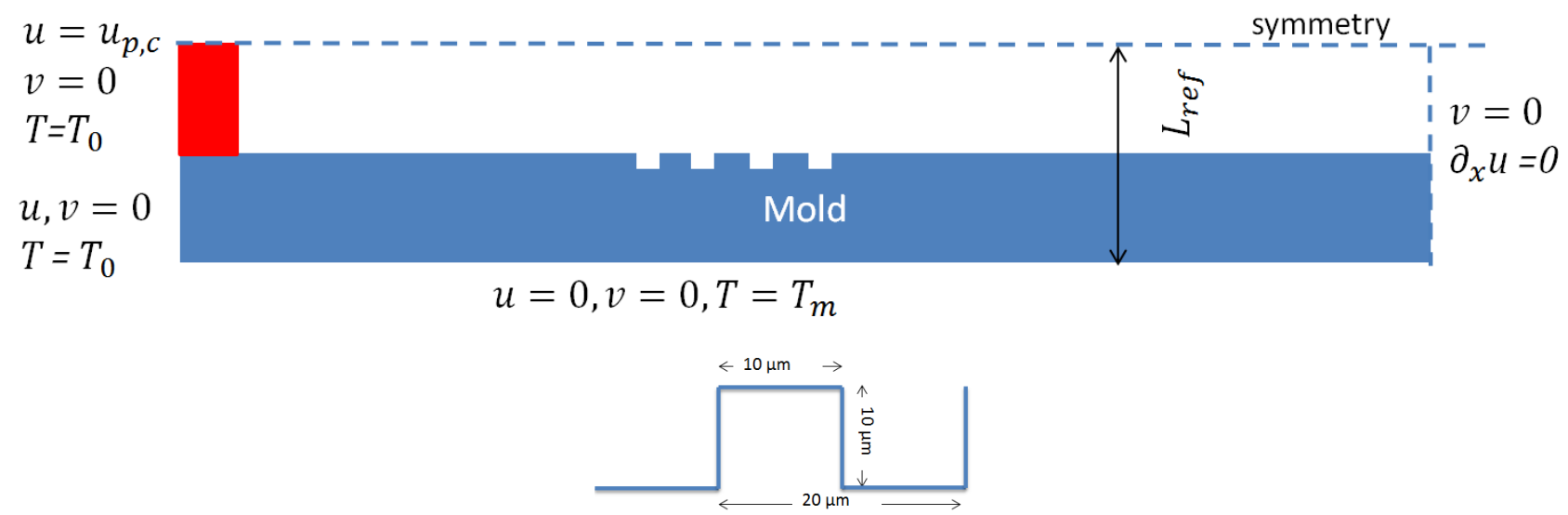

Figure 5: Schematic illustration of the two dimensional geometry and boundary conditions used for multiphase computation; zoom on the textured shape (only four ribs are considered in our computations); $u_{p, c}$ is the Poiseuille or Couette velocity profile imposed at the entrance; $T_{0}$ the initial temperature; $T_{m}$ the mould temperature.

First, we begin by solving the problem at the macroscopic scale using Rem $3 \mathrm{D} R$. The second step is to collect important data (such as temperature and velocity fields) resulting from the macroscopic simulation to feed it to the microscopic one. The delicate point is to appropriately choose at which time and where these information should be recovered. We find it logical to retrieve them exactly at the beginning of the textured zone for a maximum precision, since the microscopic simulation will focus mainly on this region. Then, injection moulding is simulated at this scale. Data coming from macroscopic results are fed as initial and boundary conditions as illustrated in the scheme of Figure 5 but for another characteristic length. Indeed, the main parameter describing this smallest level is the characteristic length $L_{r e f}$ which gives the thickness of the computational domain, equally divided between the mould and the cavity to be filled. In practice, we choose two characteristic lengths $L_{r e f}$ equal to $1 \mathrm{~mm}$ and $0.1 \mathrm{~mm}$, the smallest being related to the thermal boundary layer at melt/mould interface. For $L_{r e f}=1 \mathrm{~mm}$, the flow motion corresponds to a half Poiseuille flow and the temperature profile is better analysed than with $\operatorname{Rem} 3 \mathrm{D} R$ software. The flow rate is imposed and the initial temperature is deduced from Rem $3 \mathrm{D} \cap$ computations. For $L_{\text {ref }}=0.1 \mathrm{~mm}$, the flow motion corresponds to a pure shear flow, that is to say we impose the velocity at $y=L_{r e f} / 2$ according to the result of computations made with $L_{r e f}=1 \mathrm{~mm}$.

Computations are thus performed on a rectangular domain with a unit height where the equations have been scaled as explained in section 2.4. The main interest of the scaled equation is to work with constant numerical parameters, like time step (namely $\Delta t=0.001)$ which corresponds to a very small real time step $\left(\Delta t L_{\mathrm{ref}} / V_{\text {ref }}\right.$, see Table 3).

\begin{tabular}{|c|c|c|c|}
\hline$L_{\text {ref }}(m m)$ & $t_{\text {ref }}(s)$ & $\Delta t_{\text {real }}(s)$ & $t^{*}$ \\
\hline 1 & $1.2 \times 10^{-3}$ & $1.6 \times 10^{-6}$ & 21.6 \\
0.1 & $1.78 \times 10^{-4}$ & $1.78 \times 10^{-7}$ & 146.3 \\
\hline
\end{tabular}

Table 3: Scaled time factor, real time step and scaled filling time for a real filling time $t=0.026 \mathrm{~s}$ for the two reference lengths and a scaled time step $\Delta t=0.001$.

\subsubsection{Cavity and mould temperature determination}

Let us suppose $L_{r e f}=1 \mathrm{~mm}$ leading to a computational geometry including $0.5 \mathrm{~mm}$ of the mould and half of the cavity thickness. It is thus at macroscopic scale computation. 
At the entrance, we impose a Poiseuille flow (the exact polynomial solution) with the flow rate per unit width deduced from the actual filling flow rate $\left(Q=2.5 \times 10^{-5} / 0.015 / 2=8.33 \times 10^{-4} \mathrm{~m}^{2} / \mathrm{s}\right)$. In this particular case, the reference velocity, $V_{\text {ref }}$, will be $Q / L_{\text {ref }}=0.833 \mathrm{~m} / \mathrm{s}$.

The temperature profile at the beginning of our calculation ( $0.0725 s$ after the beginning of filling) is only partially known: simulations with $\operatorname{Rem} 3 \mathrm{D} \cap$ have shown that a central plateau and two small regions with a strong gradient near the walls could model the temperature profile (for a small Cameron number). The conductive solution when the fluid is at rest is chosen as thermal boundary condition at the entrance. As the thermal effusivity of mould is usually one hundred times bigger than that of polymer, the following relationship has been chosen for the initial temperature profile at the entrance (after scaling the interface is located at $y=0$ ):

- the stationary linear solution is imposed in the mould

$$
T(y)=T_{i}-2\left(T_{m}-T_{i}\right) y
$$

- whereas the purely conductive solution is imposed for the fluid

$$
T(y)=T_{i}+\left(T_{f}-T_{i}\right) \operatorname{erf}\left(\frac{y}{2 \sqrt{k \tilde{t} / \rho c_{p}}}\right)
$$

where $T_{i}$ is the temperature at the mould cavity surface in contact with the polymer, $T_{f}$ is the maximal temperature in the core of the flow, here $205^{\circ} C, T_{m}$ is the imposed temperature at $y=-L_{r e f} / 2$, here $35^{\circ} C$. The fictitious time $\tilde{t}$ is chosen arbitrary to fix the size of the thermal boundary layer since the real size of this thermal layer will be given by the computations after a small transient. This interface temperature is given by the analytical expression

$$
T_{i}=\frac{\sqrt{k_{m} \rho_{m} C_{p m}} T_{m}+\sqrt{k \rho C_{p}} T_{f}}{\sqrt{k_{m} \rho_{m} C_{p m}}+\sqrt{k \rho C_{p}}}
$$

which gives the steady state contact temperature between two different media for a purely conductive heat transfer [1]. In addition, the mould temperature $T_{\mathrm{m}}$ is imposed at the lower wall.

Results obtained are presented in Figures 6 and 7 where the temperature distribution is plotted on a transverse section just before the textured zone. For $y^{*}=-1 / 2$, the temperature is equal to the mould temperature, $35^{\circ} C$. For $y^{*}=+1 / 2$, it is equal to the melt temperature, $205^{\circ} \mathrm{C}$. The initial interface temperature at the scaled coordinate $y^{*}=0$ is $47^{\circ} \mathrm{C}$ with the analytic formula (27). It is shown that after a small transient this value is slightly modified along the horizontal axis as the cavity is filled, being equal to $47.8^{\circ} \mathrm{C}$ just before the textured zone.
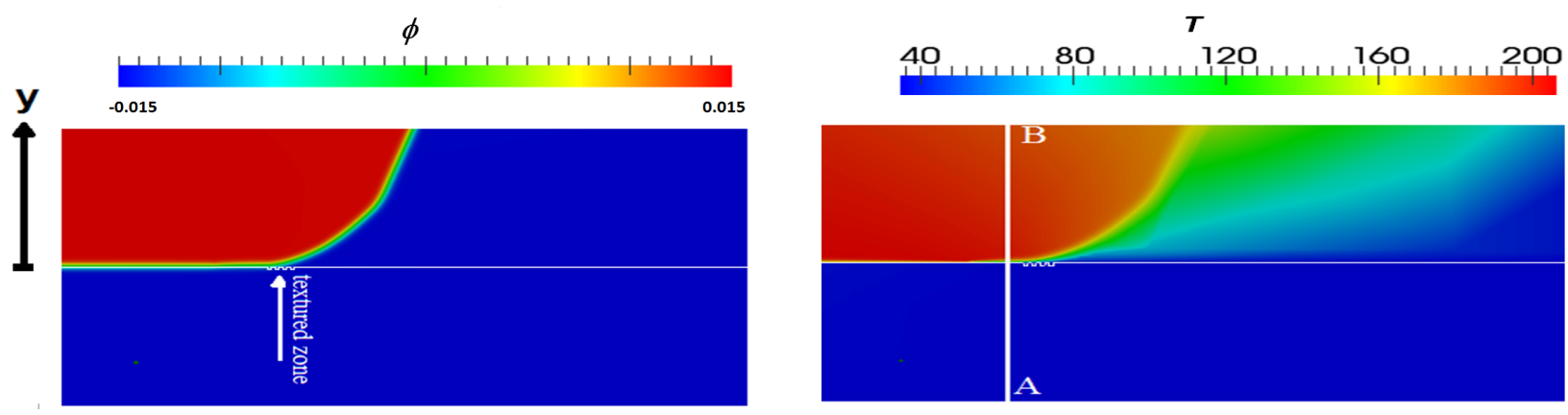

Figure 6: Flow front described by levelset $\phi_{\text {melt }}$ (a) and temperature (b) at the macroscopic level, $L_{r e f}=1 \mathrm{~mm}$.

Figure 7 shows the temperature and $x$ velocity component evolution with $y$ along the line AB shown on Figure 6b. Starting at at $y^{*}=-0.5$, the temperature increases almost linearly in the mould, then it increases from $40^{\circ} \mathrm{C}$ to $205^{\circ} \mathrm{C}$ within $0.05 \mathrm{~mm}$, and then it is almost constant. Therefore taking $L_{r e f}=0.1 \mathrm{~mm}$ will make it possible to capture the thermal gradient at the local scale, together with the flow front evolution in the micro-ribs.

Studying the thermal transfers in the mould is achievable at this scale but the cavities are hardly visible. Thus, tracking the textured zone filling remains impossible. To overcome this point, we take $L_{r e f}=0.1 \mathrm{~mm}$, as detailed in the next section. This value seems more suitable since the Figure 7 a shows that the thermal boundary layer in the melt part is located for $y<0.05 \mathrm{~mm}$. 

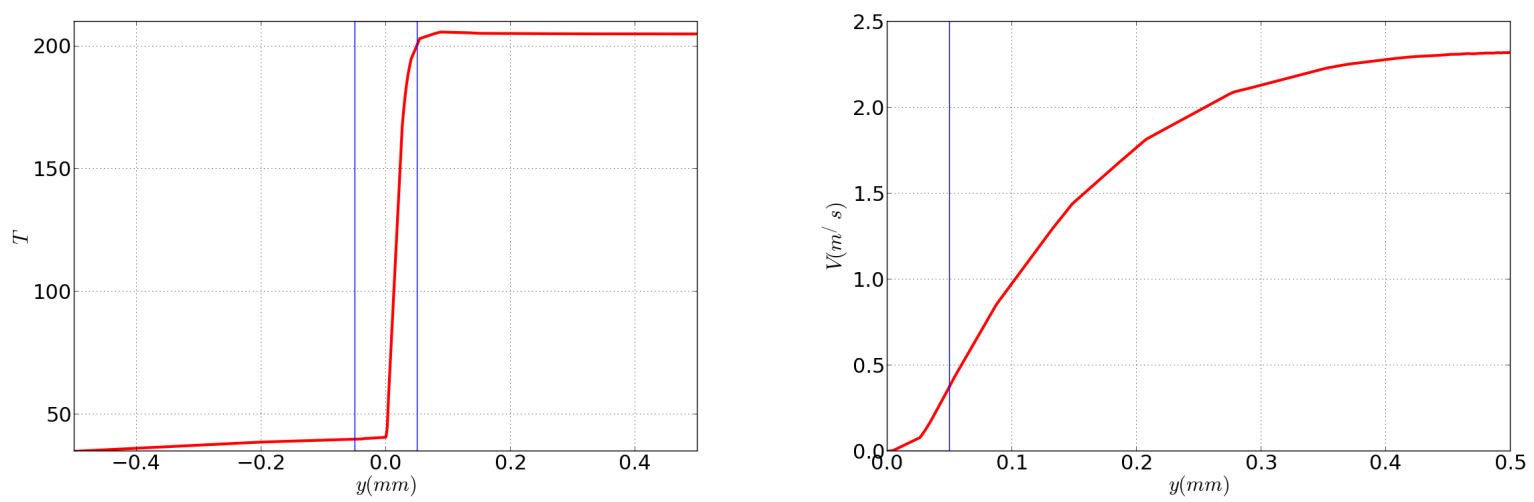

Figure 7: Temperature and velocity component along $x$ plotted on a transverse section AB depicted in Figure 6 for $L_{r e f}=1 \mathrm{~mm}$. The blue line located at $y= \pm 0.05 \mathrm{~mm}$ shows the domain studied at micro-scale if $L_{r e f}=0.1 \mathrm{~mm}$.

\subsubsection{Miscroscale Computations}

Taking $L_{r e f}=0.1 \mathrm{~mm}$ is equivalent to zooming 10 times the previous configuration. The boundary and initial conditions are recovered from this latter. The melt initial upper velocity and temperature are, respectively, equal to $0.38 \mathrm{~m} / \mathrm{s}$ and $205^{\circ} \mathrm{C}$ measured at $y=0.05 \mathrm{~mm}$ with $L_{\text {ref }}=1 \mathrm{~mm}$. For the mould temperature, it is equal to $39.85^{\circ} \mathrm{C}$ for $y=-0.05 \mathrm{~mm}$ (as seen in Figure $7 \mathrm{a}$ ). The microscopic case is carried out this smaller scale allowing a better observation of both the mould and the textured zone. Moreover, it is possible to compute a local capillary number based on the vertical velocity and on the viscosity near the melt/air interface. It is found that this number is about 200 as the cavity is filled and, in this case the role of surface tension can be neglected.

The no-flow criterion presented in Eq. (13) can play a role in this thermal layer and different values of $b$ are checked for $T_{s}=117^{\circ} \mathrm{C}$. It increases the viscosity below the solidification temperature to simulate appropriately the melt flow in this zone. In fact, higher values will lead to larger frozen layers and it will be more difficult for the fluid to fill the texture. To put this into evidence, the filling ratios (namely the ratio between surface filled over total surface of micro-cavity) are computed for various values of parameter $b$. They are reported in Table 4 and Figure 8 illustrates the different filling scenarios for $0<b<0.1$ at $t=0.1 \mathrm{~s}$. Identifying these parameters from experimental data will be the subject of future investigations.

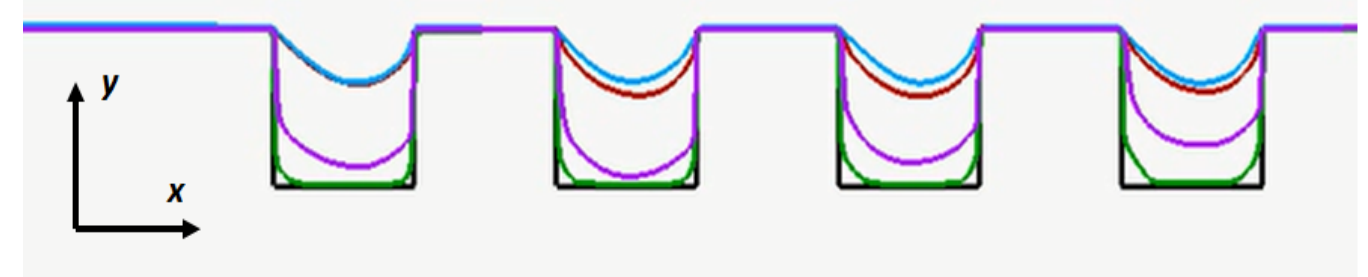

Figure 8: Texture cavities filling at $t=0.1 \mathrm{~s}$ for $L_{\text {ref }}=0.1 \mathrm{~mm}, T_{\mathrm{s}}=117^{\circ} \mathrm{C}$ for different values of $b=$ $0,0.01,0.005,0.1$, and a resolution done with no-flow criterion given by Eq. (13)

\begin{tabular}{|c|cccc|}
\hline$b$ & 0 & 0.01 & 0.05 & 0.1 \\
\hline filling rate & 0.94 & 0.65 & 0.24 & 0.17 \\
\hline
\end{tabular}

Table 4: Filling rate (surface filled/total surface of micro-cavities) as a function of the freezing parameter $b$.

The method using penalty factor, as explained in Eq. 21 gives similar results, as plotted in Figure 9 One observes that the final position of the interface (the isozero value of the modified level-set function) depends on 
the solidification temperature. Table 5 gives the filling rate for different values of $T_{s}$. As mentioned earlier, a correct solidification criterion should be related to the crystallinity ratio. Crystallization kinetics models under high stress, pressure and rate of deformation and models linking rheological behaviour and crystallinity ratio are still research domains. Therefore, a solidification temperature adjusted by comparing experimental and numerical filling rates is an acceptable solution.

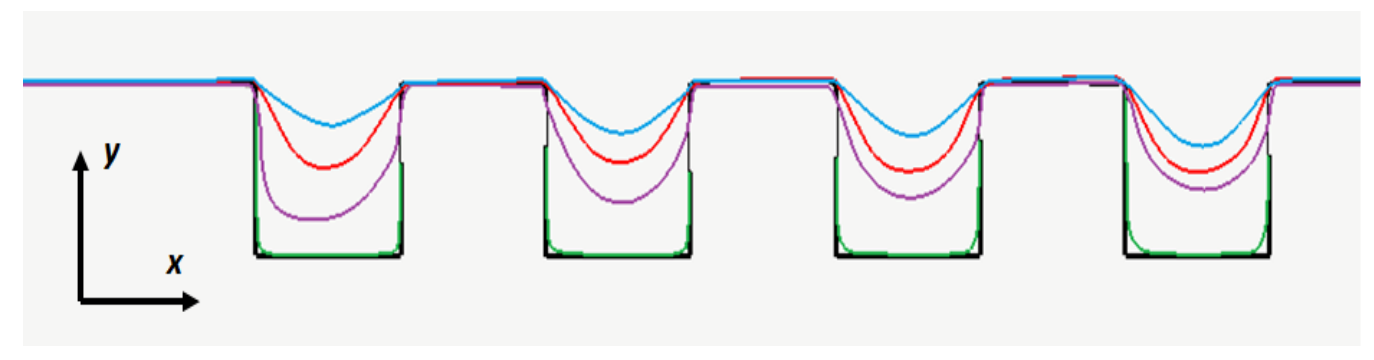

Figure 9: Texture cavities filling at $t=0.1 \mathrm{~s}$ for $L_{r e f}=0.1 \mathrm{~mm}$ and different values of $T_{s}=40,50,80,100^{\circ} \mathrm{C}$, using a penalty method.

\begin{tabular}{|c|cccc|}
\hline$T_{s}$ & 40 & 50 & 80 & 100 \\
\hline filling rate & 0.99 & 0.53 & 0.25 & 0.084 \\
\hline
\end{tabular}

Table 5: Filling rate (surface filling/surface of holes) as a function of the freezing temperature $T_{s}$.

In conclusion, two approaches to model the no-flow criterion were presented: one based on a modified WLF relationship and the other on a penalty method. Both behaviours were satisfactory and qualitatively comparable. However, the latter needs only one parameter, $T_{s}$, and has better numerical stability. The exponential factor $b$ in Eq. 13 increases drastically the viscosity resulting in ill-conditioned problems. Based on this point, further computations will be accomplished using solely the penalty method.

\section{Influence of the flow rate and mould temperature on the texture filling rate}

Earlier research in micro-injection moulding has found that high melt and mould temperatures and high injection velocity increase the filling of micro cavities [14, 42, 24]. To test the performance and efficiency of the implemented model, the effects of flow rate and of mould temperature on the filling rate were investigated and are presented hereby.

\subsection{Influence of the flow rate}

The melt and solidification temperatures are respectively set to $205^{\circ} \mathrm{C}$ and $80^{\circ} \mathrm{C}$. Three different flow rates are checked: $12.5 \mathrm{~cm}^{3} / \mathrm{s}, 25 \mathrm{~cm}^{3} / \mathrm{s}$ and $50 \mathrm{~cm}^{3} / \mathrm{s}$. Both the temperature and the velocity distribution are plotted for the section $\mathrm{AB}$ and $L_{\text {ref }}=1 \mathrm{~mm}$ (see Figures 10 ).

As expected, changing the flow rate has a clear impact on the velocity of the melt. At $y=0.05 \mathrm{~mm}$, the velocity (used later as initial conditions for the microscopic computation) increases from $0.1 \mathrm{~m} / \mathrm{s}, 0.38 \mathrm{~m} / \mathrm{s}$ to $1.5 \mathrm{~m} / \mathrm{s}$ for the three flow rates. This leads also to a decrease on the size of the boundary layer near the mould/melt interface, as seen in Figure $10 \mathrm{a}$, from $0.08 \mathrm{~mm}$ to less than $0.05 \mathrm{~mm}$. Relying on this data, one expects a better filling of cavities when the flow rate increases and thus counterbalances the effects of the premature solidification. Microscopic computations were then performed using $L_{r e f}=0.1 \mathrm{~mm}$ with initial and boundary conditions extracted from the macroscopic scale for $y= \pm 0.05 \mathrm{~mm}$ and reported in Table 6

Table 7 shows that the filling rate increases greatly from 0.02 to 0.68 , pointing out the influence of the flow rate. The Figure 10a also shows that the size of thermal layer increases for the smallest flow rate: it is around $0.08 \mathrm{~mm}$ instead of smaller than $0.05 \mathrm{~mm}$ for the other cases. This suggests perhaps to increases $L_{\text {ref }}$ at microscopic level for this lower flow rate, if we want to get a better description of this entire thermal boundary layer. 


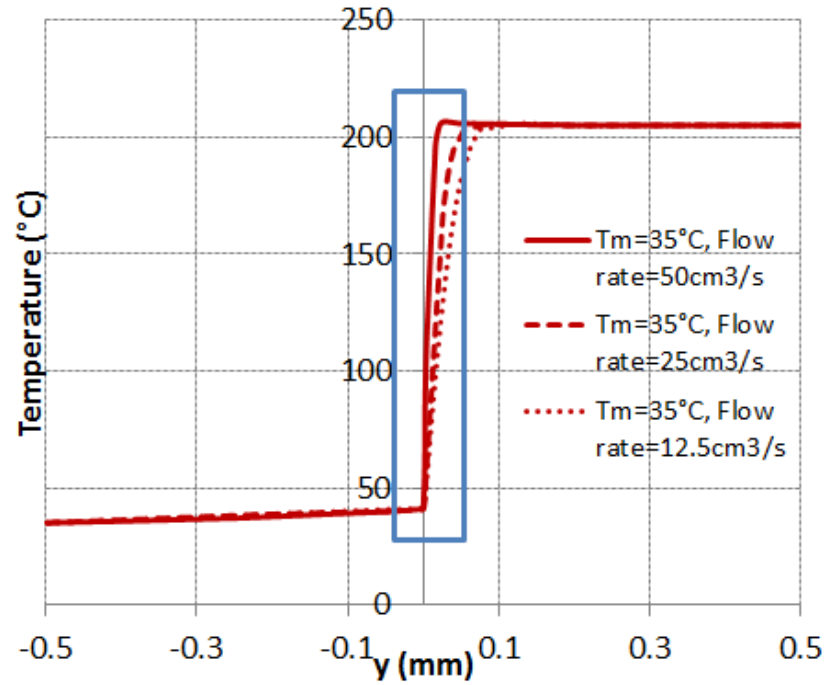

(a)

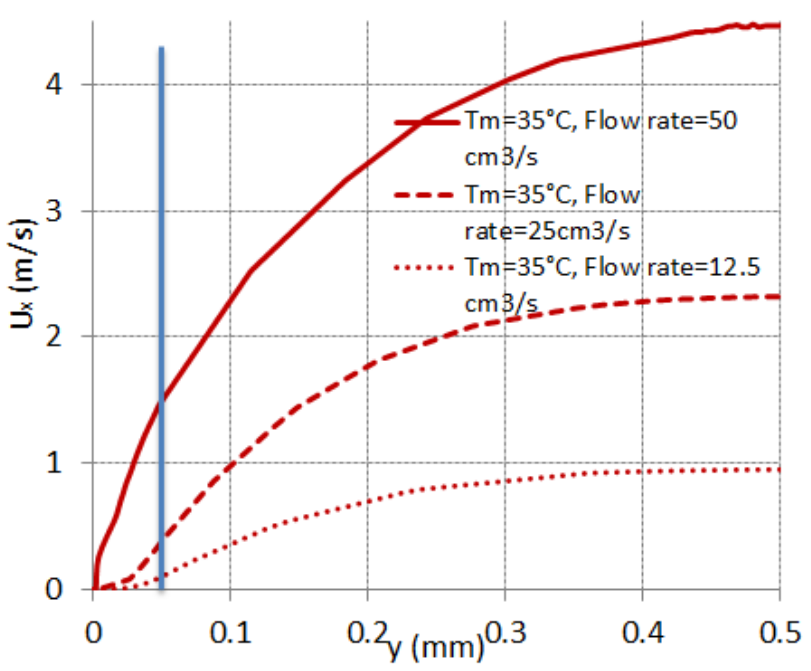

(b)

Figure 10: Illustration of the impact of changing the flow rate on the velocity and temperature profiles, plotted on the transverse section $\mathrm{AB}$ drawn in Figure $6 \mathrm{~b}$ for $L_{\mathrm{ref}}=1 \mathrm{~mm}$.

\begin{tabular}{|c|c|c|c|}
\hline$Q\left(\mathrm{~cm}^{3} / \mathrm{s}\right)$ & $T(y=-0.05)^{\circ} \mathrm{C}$ & $T(y=0.05)^{\circ} \mathrm{C}$ & $v_{x}(y=0.05) \mathrm{m} / \mathrm{s}$ \\
\hline 12.5 & 40 & 181.83 & 0.102 \\
25 & 39.93 & 200.68 & 0.380 \\
50 & 39.93 & 205.90 & 1.493 \\
\hline
\end{tabular}

Table 6: Temperatures and velocities at the boundary of the thermal layer for different flow rates. These data are used for Micro-scale computations. 


\begin{tabular}{|c|ccc|}
\hline$Q\left(\mathrm{~cm}^{3} / \mathrm{s}\right)$ & 12.5 & 25 & 50 \\
\hline filling rate & 0.02 & 0.17 & 0.68 \\
\hline
\end{tabular}

Table 7: Filling rate as a function of the increasing flow rate, for $T_{s}=80^{\circ} \mathrm{C}$.

\subsection{Influence of the temperature}

Changing the mould temperature can be used to increase the filling of the textured zone and counterbalance a premature solidification. To highlight this influence, different mould temperatures were chosen, between $35^{\circ} \mathrm{C}$ and $60^{\circ} \mathrm{C}$, while the flow rate $Q$ and the solidification temperature $T_{s}$ remain the same and are, respectively, equal to $25 \mathrm{~cm}^{3} / \mathrm{s}$ and $80^{\circ} \mathrm{C}$. Both the temperature and velocity profiles at the macroscopic level are plotted in Figure 11 for the transverse section AB. No significant impact is visible on both results. The main difference is noticeable in the mould and as expected the mould/melt interface temperature increase from $40.7^{\circ} \mathrm{C}$ to $67^{\circ} \mathrm{C}$.

Microscopic computations with $L_{\text {ref }}=0.1 \mathrm{~mm}$ were performed with the data represented in Table 8

\begin{tabular}{|c|c|c|c|}
$T_{m}$ & $T(y=-0.05)^{\circ} C$ & $T(y=0.05)^{\circ} C$ & $v_{x}(y=0.05) \mathrm{m} / \mathrm{s}$ \\
\hline 35 & 39.93 & 200.68 & 0.380 \\
40 & 44.71 & 201.42 & 0.396 \\
50 & 54.92 & 201.91 & 0.402 \\
60 & 65.46 & 201.98 & 0.406 \\
\hline
\end{tabular}

Table 8: Temperatures and velocities at the boundary of the thermal layer in which micro-scale computations are made for different mould temperatures $T_{m}$.

Table 9 shows that an increase of the mould temperature from 35 to $60{ }^{\circ} \mathrm{C}$ leads to a filling rate increase from 0.17 to 0.57 .
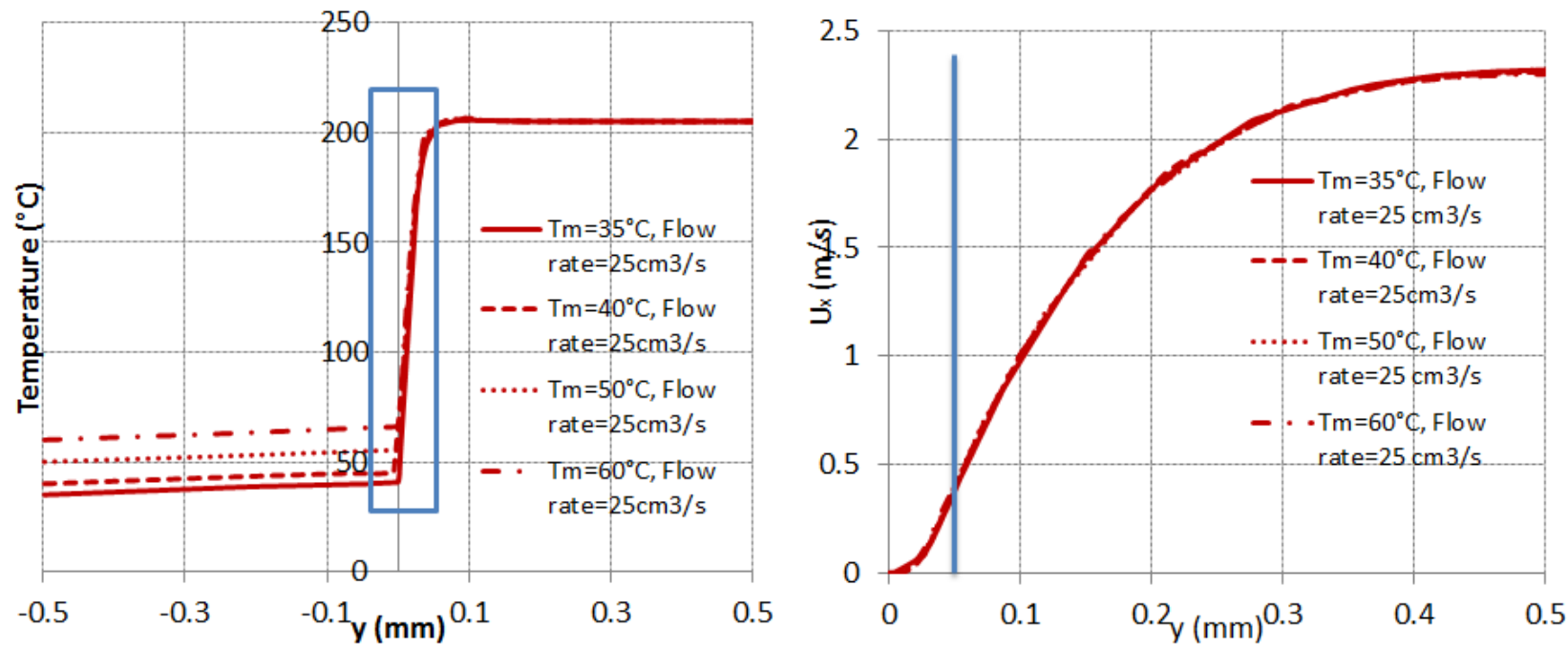

Figure 11: Impact of changing the mould temperature on the velocity and temperature profiles plotted on the transverse section $\mathrm{AB}$ drawn in Figure $6 \mathrm{~b}$ for $L_{r e f}=1 \mathrm{~mm}$.

\begin{tabular}{|c|cccc|}
\hline$T_{m}$ & 35 & 40 & 50 & 60 \\
\hline filling rate & 0.17 & 0.26 & 0.36 & 0.57 \\
\hline
\end{tabular}

Table 9: Filling rate (surface of textures filled/total surface of textures) as a function of different mould temperatures for $T_{s}=80^{\circ} \mathrm{C}$. 


\section{Conclusion}

The implemented methodology is based on a multiphase approach, which allows computing the different fields such as temperature in both mould and melt. With a classical two-phase (air/polymer) approach, mould filling computation at macroscopic level does not often need to take into account the heat transfer inside the mould since a heat flux condition can be sufficient to have a good estimation of the temperature distribution. Nevertheless, analysis of micro-texturation filling needs an accurate description of the thermal boundary layer at the polymer/mould interface. Therefore, the three-phase system coupled to anisotropic adaptation seems to be the most pertinent. For this study, we have chosen a situation for which the injection flow is rather simple (a Poiseuille profile with fountain flow) and a two dimensional configuration is sufficient to describe part filling. However, there are two different time scales corresponding to micro-features filling and the overall part filling, respectively. In fact, an accurate description of the textured zone at macro-scale would induce small mesh sizes and therefore a small time step would be required due to CFL condition. In order to reduce the computational time, computations at a micro-scale were decoupled from the ones at the macro-scale. The higher scale computations give the size of the thermal boundary layer and the velocity profile (approximated by a Couette flow) at micro-scale. The computations at the smaller scale are necessary for a better description of melt behaviour as the viscosity is subjected to two counteractions: decreasing temperature near the mould wall increases the viscosity, whereas higher shear rate decreases it. As the Williams-Landel-Ferry model reaches its limit of validity, we have checked two methods in order to better model the melt solidification near the wall: either the viscosity is drastically increased below the solidification temperature [26] or a penalty method tends to cancel the velocity in region where the temperature is below the solidification one. The two approaches give globally acceptable results, but the first method induces numerical instability due to the large difference between material viscosities. Moreover, the amplification parameter $b$ has not a real physical meaning. On the other hand, with the second approach, we can take into account the fact that the static solidification temperature can be changed if a shear rate is applied. Finally, our numerical tools allow predicting the impact of two important parameters, the mould temperature and the flow rate, on the filling rate of the micro-cavities. Although the model needs more additions to handle the complete injection cycle, the results are satisfactory and encourage pursuing this approach to such type of problems.

\section{Funding and Conflict of Interest}

R. Nakhoul has received a grant from ANR TopoInjection project which has also support this study. The authors declare also that they have no conflict of interest.

\section{References}

[1] Agassant J-F, Avenas P, Sergent J-P, Vergnes B and Vincent M (2014) Mise en forme des polymères : Approche thermomécanique de la plasturgie. Lavoisier 4ème Edition (in French).

[2] Angelov A, Coulter J (2004) Micromolding product manufacture-a progress report. Proceedings of the annual technical conference (ANTEC 2004), Chicago (IL), 16-20 May 2004

[3] Attia UM, Marson S and Alcock JR (2009) Micro-injection moulding of polymer microfluidic devices. Microfluidics and Nanofluidics 7:1-28

[4] Coupez T (1994) A mesh improvement method for 3D automatic remeshing In: Numerical Grid Generation in Computational Fluid Dynamics and Related Fields, N.P. Weatherill et al. Editors, Pineridge Press, 615-626

[5] Coupez T (2011) Metric construction by length distribution tensor and edge based error for anisotropic adaptive meshing. Journal of Computational Physics 230(7):2391-2405

[6] Coupez T, Digonnet H, Hachem E, Laure P, Silva L and Valette R (2013) Multidomain Finite Element Computations. In: Arbitrary Lagrangian-Eulerian and Fluid-Structure Interaction, John Wiley \& Sons, Inc., 221-290 
[7] Coupez T, Silva L and Hachem E (2015) Implicit Boundary and Adaptive Anisotropic Meshing. In: New Challenges in Grid Generation and Adaptivity for Scientific Computing, E. Perotto \& S. Formaggia (Eds.), Springer International Publishing, 5:1-18

[8] COMSOL Multiphysics $($ https://www.comsol.com/

[9] El Otman R, Zinet M, Boutaous M and Benhadid H (2011) Numerical simulation and thermal analysis of the filling stage in the injection molding process: Role of the mold-polymer interface. Journal of Applied Polymer Science, 121:1579-1592

[10] Francois G, Ville L, Silva L and Vincent M (2013) Multi Criteria Adaptive Meshing for Polymers Processing in Rem3D $囚$. Key Engineering Materials, 554-557:1649-1657

[11] Gruau C, Coupez T (2005) 3D tetrahedral, unstructured and anisotropic mesh generation with adaptation to natural and multidomain metric. Comput. Methods Appl. Mech. Engrg. 194(4849):4951-4976

[12] Gava A and Lucchetta G (2012) On the performance of a viscoelastic constitutive model for micro injection moulding simulations. eXPRESS Polymer Letters 6(5):417-426 DOI: 10.3144/expresspolymlett.2012.44

[13] Giboz J, Copponnex T and Mélé P. (2007) Micro-injection molding of thermoplastic polymers: a review. Journal of Micromechanics and Microengineering 17:R96

[14] Hill S, Kamper K, Dasbach U, Dopper J, Ehrfeld W and Kaupert M (1995) An investigation of computer modelling for microinjection moulding. In: Proceedings of microsym' 95.

[15] Kukla C, Loib H, Detter H and Hannenheim W (1998) Micro-injection moulding-the aims of a project partnership. Kunsts Plast Eur 88(9):6-7

[16] Larochette M, Brulez AC, Vera, J and Benayoun S (2015) Development of an instrumented mold for the replication of textured surfaces by injection molding: optimization of the replication quality. Polymer Replication on Nanoscale, 2nd International Conference, Copenhagen, Denmark.

[17] Moldflow® http://www.autodesk.com/products/moldflow/overview

[18] Piotter V, Hanemann T, Ruprecht R and Hausselt J (1997) Injection molding and related techniques for fabrication of microstructures. Microsystem Technologies 3:129-133

[19] Piotter V, Mueller K, Plewa K, Ruprecht R and Hausselt J (2002) Performance and simulation of thermoplastic micro injection molding. Microsystem Technologies 8:387-390

[20] Ramière I (2008) Convergence analysis of the Q1-finite element method for elliptic problems with non-boundary fitted meshes. International Journal for Numerical Methods in Engineering, 75(9):1007-1052.

[21] Rytka C, Kristiansen PM and Neyer A (2015) Iso- and variothermal injection compression moulding of polymer micro- and nanostructures for optical and medical applications. J. Micromechanics and Microengineering 25:065008

[22] Rytka C, Lungershausen J, Kristiansen PM and Neyer A (2016) 3D filling simulation of microand nanostructures in comparison to iso- and variothermal injection moulding trials. J. Micromechanics and Microengineering 26:065018.

[23] Rem3D® http://www.transvalor.com/en/cmspages/rem3d.7.html

[24] Sha B, Dimov S, Griffiths C and Packianather MS (2007) Investigation of micro-injection moulding: Factors affecting the replication quality. Journal of Materials Processing Technology 183:284-296. 
[25] Su YC, Shah J and Lin L (2004) Implementation and analysis of polymetric microstructure replication by micro injection moulding. Inst. Phys. Publ. J. Micromech. Microeng. 14:422.

[26] Sollogoub C, Felder E, Demay Y, Agassant J-F, Deparis P and Mikler N (2008) Thermomechanical analysis and modeling of the extrusion coating process. Polym. Eng. Sci., 48:1634-1648. doi: 10.1002/pen.21099

[27] Shen Y, Yeh S and Chen S (2002) Three-Dimensional Non-Newtonian Computations of Microinjection Molding with the Finite Element Method International Communications in Heat and Mass Transfer 29:643-652

[28] Shen Y-K, Chang C-Y, Shen Y-S, Hsu S-C and Wu M-W (2008) Analysis for microstructure of microlens arrays on micro-injection molding by numerical simulation. International Communications in Heat and Mass Transfer, 35:723-727

[29] Tolinski M (2005) Macro challenges in micromolding. Plast Eng 61(9):14-16

[30] Ville L, Silva L and Coupez T (2011) Convected level set method for the numerical simulation of fluid buckling. International Journal for Numerical Methods in Fluids 66(3):324-344.

[31] Vera J, Brulez A-C, Contraires E, Larochette M, Valette S and Benayoun S (2015) Influence of the polypropylene structure on the replication of nanostructures by injection molding. Journal of Micromechanics and Microengineering 25:115027

[32] Weber L, Ehrfeld W, Freimuth H, Lacher M, Lehr H and Pech B (1996) Micromolding: a powerful tool for large-scale production of precise microstructures. In: Proceedings of SPIE-the international society for optical engineering, Austin, TX, USA, 14-15 October 1996

[33] Weber L and Ehrfeld W (1998) Molding of microstructures for high-tech applications. In: Proceedings of the 56th annual technical conference (ANTEC 1998). Part 3 (of 3), Atlanta, GA, USA, 26-30 April 1998

[34] Weber L and Ehrfeld W (1999) Micromoulding: market position and development potential. Kunststoffe 89(10):192-202

[35] Willams ML, Landel RF and Ferry DH (1955) Temperature dependence of relaxation mechanisms in amorphous polymers and other glass-forming liquids. Journal of the American Chemical Society 77:3701-3706.

[36] Wu P H, Cheng C W, Chang C P, Wu T M and Wang J K (2011) Fabrication of large-area hydrophobic surfaces with femtosecond-laser-structured molds, Journal of Micromechanics and Microengineering 21(11):115032

[37] Xie L, Jiang B and Shen L (2011) Modelling and Simulation for Micro Injection Molding Process. INTECH Open Access Publisher.

[38] Yao D and Kim B (2002) Simulation of the filling process in micro channels for polymeric materials. Journal of Micromechanics and Microengineering 12:604

[39] Yang C, Yin X-H and Cheng G-M (2013) Microinjection molding of microsystem components: new aspects in improving performance. Journal of Micromechanics and Microengineering 23:093001

[40] Yoshii M and Kuramoto H (1994) Experimental study of transcription of minute width grooves in injection moulding. Polym. Eng. Sci. 34(15):1215.

[41] Yu L, Koh C, Lee L, Koelling K and Madou M (2002) Experimental investigation and numerical simulation of injection molding with micro-features. Polym. Eng. Sci. 42(5):871-888 
[42] Yu L, Lee L and Koelling K (2004) Flow and heat transfer simulation of injection molding with microstructures. Polym. Eng. Sci. 44(10):1866-1876

[43] Zhao J, Mayes R, Chen G, Chan PS and Xiong ZJ (2003) Polymer micromould design and micromoulding process. Plast. Rubber Compos. 32(6):240-247 